\title{
USING THE BOLMAN AND DEAL'S FOUR FRAMES IN DEVELOPING A DATA GOVERNANCE STRATEGY
}

\author{
Justin Fruehauf, Robert Morris University,jdfst18@mail.rmu.edu \\ Fahad Al-Khalifa, Robert Morris University, faast100@mail.rmu.edu \\ Joseph Coniker, Grant ThorntonLLP,joseph.coniker@us.gt.com
}

\begin{abstract}
The need for a sound data governance strategy is paramount. The problem is what constitutes a sound data governance strategy? This paper addresses this strategic dilemma by proposing that Lee Bolman and Terrence Deal's Four Frame Model of Understanding an Institution offers a strategy for developing a sound data governance and data warehousing policy. It addresses ideas proposed in the literature involving data warehousing and data governance strategies and describes the notion of the use of the Bolman and Deal frame's model as a tool for implementing a better data governance or data warehousing implementation strategy. Finally, this article offers a review of relevant literature to examine how the Bolman and Deal model can be used in existing data governance framework development models to enhance their effectiveness.
\end{abstract}

Keywords: Bolman and Deal, Frames, Data Governance, Data Warehousing, Critical Success Factors, Big Data

\section{INTRODUCTION}

As healthcare, industrial and governmental institutions confront the new era of big data and data warehousing solutions, the need for a sound data governance strategy is paramount. The problem is what constitutes a sound data governance strategy? Or more to the point, is there a strategy for developing data governance strategy and/or a data warehousing strategy? Studies suggest that implementing a data warehousing system is best performed after understanding an institution's data governance needs. This connection will be further detailed in the sections below. With this connection between data governance and data warehousing in mind, this paper addresses this strategic dilemma by proposing that Lee Bolman and Terrence Deal's Four Frame Model of Understanding an Organization offers a strategy for developing a sound data governance and data warehousing policy.

\section{BOLMAN AND DEAL}

In Reframing Organizations Lee Bolman and Terrence Deal propose an analytic tool for understanding an organization through a four "frame" model [1]. These frames are the structural, human resources, political, and symbolic frame. Each is briefly outlined below:

- Structural Frame - Bolman and Deal define the structural frame for an organization as its "rules, roles, goals, policies, technology, and environment"

- The Human Resources Frame - The key principles of the human resources frame as developed by Bolman and Deal are the "needs, skills, and relationships" or the human element of any organization.

- The Political Frame - Power and the perception of power are the heart of Bolman and Deal's political frame concept. This entails not only authority as dictated by the structural frame, but also power as gained by skill sets, personal reputation, and personality traits such as coercion.

- The Symbolic Frame - As Bolman and Deal state, it is representing part of a "vision" for the company's future

Furthermore, a detailed description of the elements of each frame is provided in the table below:

Table 1. Overview of Bolman and Deal's Four Frame Model [1]

\begin{tabular}{|l|l|l|l|l|}
\hline \multicolumn{5}{|c|}{ FRAME } \\
\hline & Structural & Human Resource & Political & Symbolic \\
\hline Metaphor for & Factory or machine & Family & Jungle & Carnival, temple, \\
\hline
\end{tabular}




\begin{tabular}{|l|l|l|l|l|}
\hline Organization & & & & theater \\
\hline $\begin{array}{l}\text { Central } \\
\text { Concepts }\end{array}$ & $\begin{array}{l}\text { Rules, roles, goals, } \\
\text { policies, } \\
\text { technologies, } \\
\text { environment }\end{array}$ & $\begin{array}{l}\text { Needs, skills, } \\
\text { relationships }\end{array}$ & $\begin{array}{l}\text { Power, conflict, } \\
\text { competition, } \\
\text { organizational } \\
\text { politics }\end{array}$ & $\begin{array}{l}\text { Culture, meaning, } \\
\text { metaphor, ritual, } \\
\text { ceremony, stories, } \\
\text { heroes }\end{array}$ \\
\hline $\begin{array}{l}\text { Image of } \\
\text { Leadership }\end{array}$ & Social architecture & Empowerment & $\begin{array}{l}\text { Advocacy and } \\
\text { political savvy }\end{array}$ & Inspiration \\
\hline $\begin{array}{l}\text { Basic } \\
\text { Leadership } \\
\text { Challenge }\end{array}$ & $\begin{array}{l}\text { Attune structure to } \\
\text { task, technology, } \\
\text { environment }\end{array}$ & $\begin{array}{l}\text { Align organizational } \\
\text { and human needs }\end{array}$ & $\begin{array}{l}\text { Develop agenda and } \\
\text { power base }\end{array}$ & $\begin{array}{l}\text { Create faith, beauty, } \\
\text { meaning }\end{array}$ \\
\hline
\end{tabular}

How this four frame model applies to data governance and data warehousing strategies forms the core of this paper and will be addressed in greater depth in the sections below.

\section{Data Warehousing}

Implementing a data warehouse requires its own methodology. A review of the literature shows that "Data warehousing methodologies share a common set of tasks, including business requirements analysis, data design, architecture design, implementation, and deployment [5]. It is the first of these points that elicits the most interest. What constitutes business requirements analysis? One definition provided by previous research states "analysis is used to elicit the business questions from the intended users of the data warehouse. Business questions are decision support or analytic questions that managers typically pose. After all the business questions are elicited, they are prioritized by asking the users to rate the questions or by estimating the risk associated with the solutions needed for the questions [5]. Yet research shows that up to $50 \%$ of data warehousing initiatives fail [5].

One study suggests that Rockart's CSF method provides a method to ensure the successful implementation of a data warehouse system [4]. Rockart observed the problem of defining concisely exactly what information senior manager's required [4]. In response he created the Critical Success Factors (CSF) method to make needs explicit. The CSF method requires two to three rounds of interviews with key institutional executives. "The objective of the first interview was: to understand the executive's goals, to define the CSFs supporting the goals, to identify an initial set of measures for the CSFs, and to consider combining, restating, or eliminating CSFs. During the second interview, results of the first interview were reviewed; the CSFs were "sharpened up;" and measures and reports showing data/information was discussed in detail [4]. The role of each round of interview is elucidated in the diagram below:

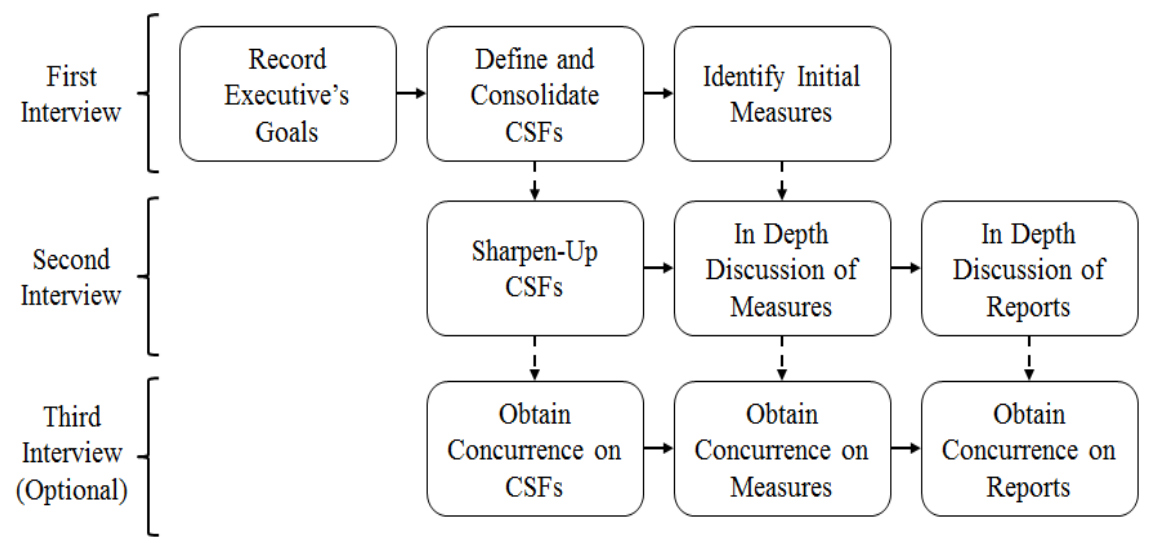

Figure 7. Rockart's CSF Method

(Kimpel, 2013)

CSF theory uses a set of questions to determine the critical success factors identified by the interviewed executives [2]. Example questions include: 
- "Will you please tell me, in whatever order they come to mind, those things that you see as critical success factors in your job at this time?"

- "Let me ask the same question concerning critical success factors in another way. In what one, two or three areas would failure to perform well hurt you the most? In short, where would you most hate to see something go wrong?"

- $\quad$ Assume you are placed in a dark room with no access to the outside world, except for food and water, today. What would you most want to know about the business when you came out three months later?"

In arguing for the use of Rockart's CSF theory as a means of increasing the success of data warehousing implementations, the study's author quotes Bullen and Rockart as stating "One should spend time with the people in the company who are sponsoring the study. Their insights into the company, its strategy, environment, current problems and opportunities are invaluable. Internal company political issues should be probed, where possible, with these company contacts since these are important. All of this background is highly useful for conducting each interview smoothly and intelligently. [2] [4].

While CSF theory suggests that understanding "environment" or culture is critical, Rockart offers little in the way of determining what elements factor into this. This creates voids in the understanding of the true layers of an organization. Bolman and Deal's Four Frame Model of Understanding an Organization offer a means of assessing these layers. By crafting questions that address the human resource, symbolic, structural, and political frames, a fuller understanding of the inner workings of the institution can be achieved. This in turn can lead to a greater success rate for developing a data warehousing or data governance plan.

Each executive, while having an understanding for their own business needs, may not be fully aware of how those needs conflict or interact with the work of others. Furthermore, the data needed to address their particular needs (and thus the success factors for a data warehousing or data governance system) may only be accessible through the cooperation of other employees at the institution. This is what Rockart refers to when stating that it is critical to spend time with people at the institution. By observing these staff interactions through the four lenses of human resources, politics, symbolism, and structure, as proposed by the Bolman and Deal model, a greater understanding of the whole organization is possible. This in turn can contribute to greater support for an institution's data governance or data warehousing strategy. The greater there is support for the strategy, the greater the chances for the implementation to succeed.

\section{Data Governance}

Khatri and Brown define data governance as what decisions must be made to ensure effective management and use of IT (decision domains) and who makes the decisions (locus of accountability for decision-making) [3]. Furthermore, they claim that "in light of the opportunities to leverage data assets as well ensure legislative compliance to mandates such as the Sarbanes-Oxley (SOX) Act and Basel II, data governance has also recently been given significant prominence in practitioners' conferences, such as TDWI (The Data Warehousing Institute) World Conference and DAMA (Data Management Association) International Symposium" [3]. The focus on data governance given by organizations such as the Data Warehousing Institute and Data Management Association reinforces the strong connection between data governance and data warehousing. As previously stated this bond makes it paramount that any strategy for implementing a data governance policy and or a data warehousing solution uses the best tools to maximize the chances for success.

The authors propose a framework for data governance as defined by five decision domains; data principles, data quality, metadata, data access, and data lifecycle [3]. These domains are outlined in the chart below.

Table 2. Framework for Data Decision Domains

\begin{tabular}{|c|c|c|}
\hline $\begin{array}{c}\text { Data Governance } \\
\text { Domains }\end{array}$ & \multicolumn{1}{|c|}{ Domain Decisions } & $\begin{array}{c}\text { Potential Roles or Locus } \\
\text { of Accountability }\end{array}$ \\
\hline Data Principles & $\bullet$ What are the uses of data for the business? & $\bullet$ Data owner/trustee \\
\hline
\end{tabular}




\begin{tabular}{|c|c|c|}
\hline $\begin{array}{l}- \text { Clarifying the role of } \\
\text { data as an asset }\end{array}$ & $\begin{array}{l}\text { - What are the mechanisms for communicating } \\
\text { business uses of data on an ongoing basis? } \\
\text { - What are the desirable behaviors for employing } \\
\text { data as assets? } \\
\text { - How are opportunities for sharing and reuse of } \\
\text { data identified? } \\
\text { - How does the regulatory environment influence } \\
\text { the business uses of data? }\end{array}$ & $\begin{array}{l}\text { - Data custodian } \\
\text { - Data steward } \\
\text { - Data producer/supplier } \\
\text { - Data consumer } \\
\text { - Enterprise Data Committee/ } \\
\text { Council }\end{array}$ \\
\hline $\begin{array}{l}\text { Data Quality } \\
\text { - Establishing the } \\
\text { requirements of } \\
\text { intended use of data }\end{array}$ & $\begin{array}{l}\text { - What are the standards for data quality with } \\
\text { respect to accuracy, timeliness, completeness and } \\
\text { credibility? } \\
\text { - What is the program for establishing and } \\
\text { communicating data quality? } \\
\text { - How will data quality as well as the associated } \\
\text { program be evaluated? }\end{array}$ & $\begin{array}{l}\text { - Data owner } \\
\text { - Subject matter expert } \\
\text { - Data quality manager } \\
\text { - Data quality analyst }\end{array}$ \\
\hline $\begin{array}{l}\text { Metadata } \\
\text { - Establishing the } \\
\text { semantics or } \\
\text { "content" of data so } \\
\text { that it is interpretable } \\
\text { by the users }\end{array}$ & $\begin{array}{l}\text { - What is the program for documenting the } \\
\text { semantics of data? } \\
\text { - How will data be consistently defined and } \\
\text { modeled so that it is interpretable? } \\
\text { - What is the plan to keep different types of } \\
\text { metadata up-to-date? }\end{array}$ & $\begin{array}{l}\text { - Enterprise data architect } \\
\text { - Enterprise data modeler } \\
\text { - Data modeling engineer } \\
\text { - Data architect } \\
\text { - Enterprise Architecture } \\
\text { Committee }\end{array}$ \\
\hline $\begin{array}{l}\text { Data Access } \\
\text { - Specifying access } \\
\text { requirements of data }\end{array}$ & $\begin{array}{l}\text { - What is the business value of data? } \\
\text { - How will risk assessment be conducted on an } \\
\text { ongoing basis? } \\
\text { - How will assessment results be integrated with } \\
\text { the overall compliance monitoring efforts? } \\
\text { - What are data access standards and } \\
\text { procedures? } \\
\text { - What is the program for periodic monitoring } \\
\text { and audit for compliance? } \\
\text { - How is security awareness and education } \\
\text { disseminated? } \\
\text { - What is the program for backup and recovery? }\end{array}$ & $\begin{array}{l}\text { - Data owner } \\
\text { - Data beneficiary } \\
\text { - Chief information security } \\
\text { officer } \\
\text { - Data security officer } \\
\text { - Technical security analyst } \\
\text { - Enterprise Architecture } \\
\text { Development Committee }\end{array}$ \\
\hline $\begin{array}{l}\text { Data Lifecycle } \\
\text { - Determining the } \\
\text { definition, production, } \\
\text { retention and } \\
\text { retirement of data }\end{array}$ & $\begin{array}{l}\text { - How is data inventoried? } \\
\text { - What is the program for data definition, } \\
\text { production, retention, and retirement for } \\
\text { different types of data? } \\
\text { - How do the compliance issues related to } \\
\text { legislation affect data retention and archiving? }\end{array}$ & $\begin{array}{l}\text { - Enterprise data architect } \\
\text { - Information chain manager }\end{array}$ \\
\hline
\end{tabular}

While elements of all of the above cited domains pertain to the notions of Bolman and Deal's four frames, of particular relevance are the domains of "Data Principles" and "Data Access". Indeed the domain decisions for both of these areas are critical to the success of any data warehousing or data governance initiative. Furthermore, they both generate institutional questions that parallel the four frames of human resources, politics, symbolism, and structure [1]. Using these four frames when assessing the answers to these domain decision questions can only strengthen any data governance policy or data warehousing implementation strategy.

\section{Data Governance and Data Warehousing in Industry}

The relevance and utility of the Bolman and Deal's Four Frame Model of Understanding an Organization are also applicable to the strategies used by data governance and data warehousing solution purveyors. A review of literature from industry-recognized data warehousing and data governance leaders produces yet another definition of data governance. Grant Thornton maintains "a data governance framework establishes strategies, objectives and policies for effectively managing an organization's data. It consists of the people, processes, structure and 


\section{Issues in Information Systems \\ Volume 16, Issue II, pp. 161-167, 2015}

architecture required to manage the availability, usability, integrity, consistency and auditability of secure data [6]." The elements of a data governance framework are further enumerated as the following:

- Includes definitions of term, metrics, items, customers and related elements (Structure)

- Distinguishes dimension values from the analytics of hierarchy definition (Structure)

- Makes/collects/aligns rules (Process)

- Assigns accountabilities to resolve issues (Process)

- Organizes data stewards and governance bodies (People)

- Monitors/enforces compliance while providing ongoing support to and change management for broad stakeholders (Architecture) [6]

Industry professionals, such as those at Grant Thornton, recognize the importance of understanding an organization's culture in order to implement an effective data governance or data warehousing strategy. "Leading companies take the time to put a data governance framework in place. A framework should be relevant to both their business strategy and application footprint, and enable process improvement [6]." The notion of creating a data governance framework that is relevant to a business strategy directly ties in to understanding the totality of the organization. The four frames model of Bolman and Deal act as a tool to accomplish this task and thus create a sound data governance framework.

In order to understand the people and processes of an organization, an understanding of the structural frame, human resources frame, political frame, and symbolic frame is necessary. Observing the organization using the four lenses fosters the understanding of the multitude of connections and inter-dependencies of the institution that may otherwise go un-noticed. These connections can be critical to the success of a data governance framework. "The core of data governance is change management through human workflow. The workflow aspect of governance allows requestors to participate directly with the change management process [6]." The ideas of management and workflow pertain to understanding the relationships of the people at an institution. In order to achieve success this requires that all pertinent people believe in the proposed solution.

Again, using the Bolman and Deal four frames model allows for more in-depth analysis of the organization and hopefully greater success with achieving change in management and workflow. People at the institution are accepted for a defined role. They have the ability to define the hierarchy and relationships of data for their expertise. However there would be governed controls in place to prevent from changing the meta-data or the data value at the atomic level. The human resource function would define the elements of an employee including employee ID, job title, ethicist etc. The human resource function would also maintain the higher key for the employee for internal performance management reviews. However, this same employee would have a different reporting hierarchy for job reporting or departmental activity. For example an employee in a bank could relate to a sales territory that includes the branch that the employee covers. In this case the HR manger would not have control to change the sales hierarchy.

The inclusion of defining terms, items, etc. as a key element in a data governance framework touches upon political frame and human resource frame as a way of defining the culture of an organization. "Without a common language, data cannot communicate successfully across systems and people can't be optimized to improve organizational processes [6]." In order to achieve a standardized terminology is it critical to understand the entire culture of the institution. An important element of culture relates to how human beings interact with each other. There is a level of respect and common understanding amongst the broad parties. As it relates to terminology, this relates to the core elements of communication. For people to communicate, and form a culture, they most speak, or at least understand the language. Data governance provide the terminology, the code, values, hierarchies for systems to speak, which in turn allow people to better communicate. However, the culture aspect of respect and intent would still need to be addressed in order for people to act to work together toward a common goal.

Using Bolman and Deal's four frame model to understand the interactions of the people of an institution allows for a more developed data governance framework. This is critical to the success of data governance and data warehousing system implementation in order to align it with the business goals of the organization. "The key to mastering data is not necessarily in the data itself, but how you relate it to the proper business context of what the data represents [6]." 


\section{Issues in Information Systems \\ Volume 16, Issue II, pp. 161-167, 2015}

Data governance is the easiest and most effective way to set the direction on the use of data across a disparate set of applications. Because the user-base for any one subject of data is diverse, the ownership of the topic can exist in a silo, creating one-off applications claiming to be the source of truth of the company on that particular subject. As a more granular level example of how a full understanding of an organization's interactions impacts data governance, consider an institution's financial reporting system. A financial closing application may in fact be the source of truth for the general ledger trial balance data, but without out data governance and integration, journal details, payable vendor information and customer revenue quickly become segmented, and one version of the truth become hidden or becomes a fiction and does not exist. Using the Bolman and Deal four frames model when assessing the needs for a data governance framework creates an atmosphere in which the role and functions of the users of these disparate systems can be not only discovered and understood, but linked to each other, thus breaking down the silo effect and creating a stronger data governance model. By engaging these users the success level of the new data governance framework and data warehousing system acceptance and use can increase.

The above example gets to the heart of implementing an effective data governance framework; understanding not just the workflow of data, but how users, or the human element of an organization's information system, interact with the data. The Grant Thornton model states data governance is not just workflow; it also includes the concept of the RACI model to help identify roles and responsibilities during a change process [6].

The RACI model is an acronym for the following:

$\mathrm{R}=$ Responsible: the person or group that owns the data

$\mathrm{A}=$ Accountable: the person or group that must approve the requested change

$\mathrm{C}=$ Consulted: the person or group that has information that is necessary to complete the data

I = Informed: the person or group that should be informed about the data change [6]

The use of the "RACI" model in the system demonstrates the importance of the link between information system users and data systems. The use of the Bolman and Deal four frames model, accounting for structure, human resources, politics, and symbolism, acts not as a replacement for the RACI model, but as an additional tool to expound upon the RACI model and thus creating a more complete understanding of an organizations functions and interactions. In this instance as each facet of the RACI model is investigated (responsibility, accountability, consultation, informing) it can be further broken down and examined through each of the four frames. By understanding the political context for those responsible or accountable, the structural and symbolic elements for those individuals who should be consulted or informed, etc. Understanding these facets in-depth facilitates the creation of an effective data governance policy. Having such a framework enables the proper implementation and acceptance of a data warehousing system.

\section{CONCLUSIONS}

As information systems increase in complexity, capturing more data in shorter periods of time, the need for an institution to develop a framework for both storing and analyzing this data becomes paramount. This need forms the basis of data governance and its related implementation of a data warehousing system. While the need for data governance frameworks and data warehousing systems is recognized, implementation of systems suffers from a high rate of failure.

It is hypothesized that basing a solution on business requirements alone is a critical reason for the lack of acceptance of data governance and data warehousing solutions. Successful implementation requires a more in-depth understanding of the organization and how its personnel interact both with each other and the data. A review of the literature and industry practices shows many approaches to developing this understanding.

This paper concludes that the inclusion of Lee Bolman and Terrence Deal's Four Frame Model of Understanding an Organization as an additional investigative tool increases the understanding an organizations regardless of the approach taken. Examining an organization through the four different frames of human resources, structure, symbolism, and politics creates the potential to uncover connections that would otherwise remain hidden. The discovery of these connections and their impact on an organization can mean the difference between success and failure of a data governance framework and data warehousing system. 


\section{Issues in Information Systems}

Volume 16, Issue II, pp. 161-167, 2015

\section{REFERENCES}

1. Bolman, L. and Deal, T. (2008). Reframing Organizations 4th Edition. San Francisco. Jossey-Bass

2. Bullen, C. and Rockart, J. (1981). A Primer on Critical Success Factors.

3. Khatri, V., \& Brown, C. V. (2010). Designing Data Governance. Communications of the ACM, 53(1), 148-152. doi:10.1145/1629175.1629210

4. Kimpel, J. (2013). Critical Success Factors for Data Warehousing: A Classic Answer to a Modern Question. Issues in Information Systems, 14(1), 376-384.

5. Sen, A., \& Sinha, A. P. (2005). A COMPARISON OF DATA WAREHOUSING METHODOLOGIES. Communications of the ACM, 48(3), 79-84. doi:10.1145/1047671.1047673

6. Coniker, Joseph. 2012. Best of Data Governance. Whitepaper published by Grant Thornton, LLP 